\title{
Uma reflexão autoenográfica sobre a aprendizagem e o ensino do desenho
}

\author{
Altamir Moreira (UFSM)
}

\section{RESUMO}

Esse texto aborda o tema da aprendizagem e do ensino de desenho a partir de uma vivência pessoal. Tem o objetivo de compartilhar experiências sobre um contexto específico, passível de comparações com outros casos desse campo de estudos. A partir da perspectiva autoetnográfica de David M. Hayano (1979), constrói uma narrativa biográfica cronológica. Apresenta uma síntese descritiva de eventos cotidianos relacionados à problemática do desenvolvimento de habilidades técnicas do desenho figurativo. Descreve algumas das dificuldades encontradas durante as atividades de ensino de desenho em cursos de graduação na área de artes visuais. Relaciona algumas das estratégias utilizadas para superá-las, e finaliza com uma reflexão sobre o papel das repetições e correções na aquisição destas competências.

PALAVRAS-CHAVE: Desenho; Figura Humana; Autoetnografia; Aprendizagem;

Ensino.

\section{ABSTRACT}

This text addresses the theme of learning and teaching drawing from a personal experience. It aims to share knowledge about a specific context, which can be compared with other cases in this field of study. Based on the Auto-Ethnographic perspective of David M. Hayano (1979), it constructs a chronological biographical narrative. It presents a descriptive synthesis of everyday events related to the problem of the development of technical skills of figurative drawing. It describes some of the difficulties encountered during drawing teaching activities in undergraduate courses in the field of visual arts. It lists some of the strategies used to overcome them, and ends with a reflection on the role of repetitions and corrections in the acquisition of these competences.

KEY WORDS: Drawing; Human figure; Auto-Ethnography; Learning; Teaching . 


\section{A aprendizagem lúdica do desenho}

Neste ensaio pretendo refletir sobre o desenho de observação, enfatizando duas questões frequentemente interrelacionadas: Como se aprende a desenhar? E, como a reflexão, sobre a aprendizagem do desenho, pode nos auxiliar no ensino desta habilidade. Entretanto, desde já, acho justo informar o leitor que a minha formação acadêmica não foi voltada ao campo do ensino da arte e, como resultado disso, não domino amplos fundamentos desta área. Embora eu trabalhe, a mais de uma década, com disciplinas relacionadas à prática de desenho de observação e desenho da figura humana, meus estudos têm sido direcionados, prioritariamente, ao campo técnico da anatomia, proporções e linguagens artísticas. A área de pesquisa teórica, em que atuo, é voltada ao foco de interesse desenvolvido em minha pós-graduação no campo da história, teoria, e crítica da arte, com ênfase em estudos de iconografia. Por isso, compreendo que eu possa ser questionado sobre a pertinência de desenvolver um texto relacionado ao campo da aprendizagem e do ensino, e discorrer sobre um tema do qual não detenho as necessárias credenciais teóricas. Mas, acredito que, em parte, o problema possa ser relevado, uma vez que o interesse desta reflexão vai além das minhas idiossincrasias, ao se considerar a possível abrangência dos problemas expostos no breve relato de base autoetnográfica que compartilho.

A opção pela abordagem autoetnográfica justifica-se pelo tipo de ênfase planejada para esse texto, que não busca discutir teorias históricas da aprendizagem, mas, sim, desenvolver uma reflexão básica, embasada em vivências pessoais e descrições de experiências práticas na área do desenho de observação. Uma das características compartilhadas por autoetnógrafos, segundo David M. Hayano (1979, p. 100) é a de possuírem qualidades que os permitem autoidentificarem- 


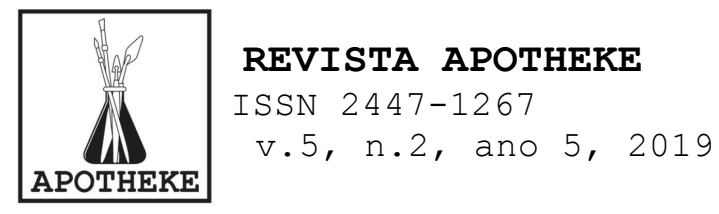

se com determinados grupos de estudo, de modo que possam ser reconhecidos com membro destes. No meu caso, o fato de ter pertencido a um grupo de estudantes que passou por determinado processo de aprendizagem em artes, e, atualmente, integrar o grupo dos professores que se dedicam à atividade de ensino do desenho.

Em termos gerais, o aprendizado do desenho começa na infância a partir do prazer visual, e das sensações motoras, desencadeados pelos traços desordenados. Evolui para formas simbólicas com linhas progressivamente melhor controladas, até chegar às configurações reconhecíveis pela associação visual às formas da natureza nele representadas. Já, na adolescência, alguns progridem para as etapas mais apuradas do desenho realista, outros optam por abordagens mais pessoais e estilizadas, e outros abandonam o interesse pelo desenho, permanecendo com o nível de habilidade que lograram obter até esta fase. No relato a seguir, busco resgatar memórias associadas a algumas dessas etapas, e evidenciar alguns focos de interesse envolvidos na realização de desenhos e algumas das dificuldades enfrentadas.

Entre as memórias que consigo reconstituir sobre o meu aprendizado do desenho, destaco algumas situações relacionadas aos focos temporários de interesse. Em um período situado, aproximadamente, entre os quatro e os seis anos, eu gostava muito de desenhar com caneta esferográfica comum, com tinta azul, talvez por ser o material gráfico mais acessível e disponível em minha casa. Embora, seja provável que eu tenha passado, regularmente, pelos diferentes níveis de garatujas e ordenação de traços, não foram conservados registros gráficos daquela época, e devido à idade em que isto ocorreu, eu não guardo memórias deles.

Lembro da satisfação que tive no dia em que minha mãe comprou canetas esferográficas coloridas: preta, verde e vermelha. Eu, finalmente, podia usar cores nas cenas que eu 


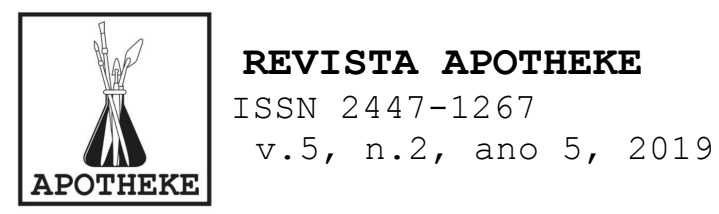

gostava de desenhar: árvores com frutas e pessoas envolvidas em colhê-los. Estes desenhos possuíam formas bastante sintéticas e estereotipadas, e imitavam alguns detalhes esquemáticos que ela havia me ensinado. Mesmo assim, eu gostava de repeti-los sobre antigos cadernos, e papéis de embrulho. Depois desta fase, passei por um período cujo foco era o desenho de flores. Era o momento em que eu começava a descobrir a variedade das formas das pétalas e folhas, ordenando-as em séries. Não lembro se cheguei a desenvolver algum interesse por desenhar flores a partir da observação direta da natureza, mas sim, que gostava de descobrir as possibilidades existentes para se criar novas flores. Mas, como meu repertório de formas ainda era limitado, recorri ao conhecimento de vizinhos e conhecidos. A cada pessoa que chegava em minha casa, eu solicitava que me mostrasse como ela desenhava flores, e depois ao lado do desenho solicitado eu tentava repetir os traços e compreender como aquelas formas tinham sido feitas.

Depois, por influência de um irmão maior, passei a desenvolver interesse por histórias em quadrinhos da Disney. Frequentemente, insistia que minha mãe as lesse para mim, e, logo depois, eu tentava desenhar alguns dos personagens. Mas, como eu quase nunca ficava satisfeito com os resultados, ela sugeriu a utilização do papel carbono para copiá-los. Então eu passei a repassar com canetas as linhas de contorno de alguns personagens, repetindo determinadas poses, várias vezes, até o limite em que as folhas de carbono perdiam parte a pigmentação ou rasgavam, impedindo a reutilização. Ainda nessa época, de idade pré-escolar, para que eu pudesse ler sozinho as histórias que eu apreciava, ela passou a ensinarme a leitura e a escrita. Por meio de cartilhas emprestadas de vizinhos, instruiu-me na leitura das letras de forma e no uso do lápis para a escrita de letras cursivas. Embora, ela advertisse que quando chegasse a idade escolar eu teria que 


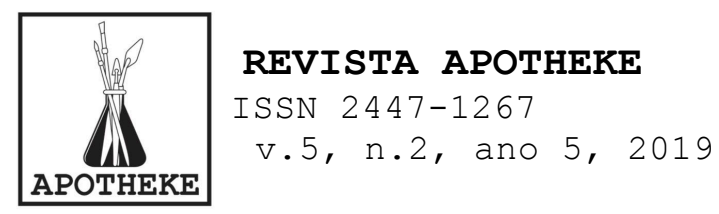

usar apenas o lápis de grafite comum, eu, ainda, preferia as canetas esferográficas para escrever e desenhar, mesmo que isto me custasse a possibilidade de corrigir erros.

Algum tempo depois, eu ganhei uma caixa com seis lápis de cores e um caderno de desenho. Quando meus pais saíram trabalhar em um local próximo de casa ${ }^{2}$ eu decidi pintar um ramalhete de flores a partir de um padrão de desenho decorativo impresso no tecido de um cobertor. Nesse ponto, eu já havia desenvolvido, em nível básico, a habilidade de reproduzir desenhos simples por meio da observação e recorria, com menor frequência, ao uso do papel carbono. Foi uma das primeiras vezes em que eu notei reações de surpresa com o resultado. Era um desenho realizado sobre papel tipo ofício, em dimensão maior do que aqueles que, até então, eu costumava realizar, com vários detalhes e razoavelmente colorido. Meus pais quiseram saber se eu havia utilizado algum meio de cópia. Mas, já não havia tal necessidade, por ser tratar de mais um desenho de flores, tema com o qual eu já estava familiarizado. Então, percebi que para eles havia algo de importante naquele trabalho, em específico, pois o guardaram e passaram a mostrar, com orgulho, a cada pessoa que nos visitava.

Em 1979, ainda com seis anos eu passei a frequentar a primeira série do ensino básico. Nessa época eu já lia histórias em quadrinhos e sabia escrever frases básicas em letra cursiva. Mas, mesmo assim essa etapa foi desafiadora, pois a professora da pequena escola do interior utilizava um método diferenciado. Ela ensinava primeiro as letras de imprensa com caixa baixa, e somente na série seguinte passava a nos habilitar para o uso das letras cursivas. Desse modo, a

\footnotetext{
2 Em 1979 eu tinha seis anos e morava com meus pais que eram agricultores no interior do município de Faxinal do Soturno, RS. Geralmente o acesso à primeira série se dava após os sete anos, mas minha matrícula foi aceita porque a idade escolar recomendada seria alcançada ainda no primeiro semestre daquele ano.
} 


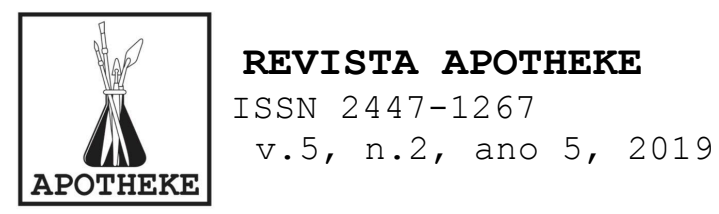

minha experiência anterior neste tipo de escrita, ainda não representava uma vantagem. Mas, achei interessante a abordagem que ela utilizava para ensinar as formas das letras e números, por meio de desenhos figurativos. Lembro que as vogais, geralmente, eram representadas sob a forma de frutas com parte do caule e folhas. Os números apresentavam rostos de personagens, palhaços e animais. Os exercícios iniciais consistiam em repetir os desenhos em longas séries nas linhas do caderno. Ambas coisas não me eram estranhas e, particularmente, me agradavam: o desenho das formas e o recurso à repetição. Somente após a fase de domínio das formas da figura, os detalhes dos personagens eram abandonados e passávamos a utilizar apenas a estrutura já aprendida, ou seja, as linhas fundamentais para a representação de letras do alfabeto latino, e números indoarábicos.

Nos cinco anos seguintes o desenho passou a fazer parte de minhas atividades cotidianas, como um tipo de brincadeira. Por um breve tempo utilizei uma espécie de lousa formada por uma laje de pedra de areia sobre a qual eu desenhava com outras pequenas pedras que possuíam uma camada externa colorida ${ }^{4}$ além do eventual uso do pigmento de folhas verdes esmagadas. Os desenhos, após concluídos, eram apagados pela fricção de outro pedaço de pedra de areia. Esses, possuíam formas simplificadas, pois as linhas desenhadas com pedras não eram muito nítidas. Mas, era estimulante toda vez que, no caminho de três quilômetros até escola rural onde estudava,

\footnotetext{
3 Pedra de areia, arenito, ou pedra grês: rocha sedimentar resultante da compactação e litificação de areias, normalmente composto normalmente por quartzo e feldspatos.

4 Nessa região do Rio Grande do Sul, nas encostas do Planalto Meridional, algumas rochas de basalto, sujeitas ao intemperismo de milhares de anos, passam por um processo natural de decomposição, cujas diferentes fases geram rochas com variantes cromáticos que vão das cores esbranquiçadas às avermelhadas, laranjas, amarelas e cinzas esverdeados.
} 


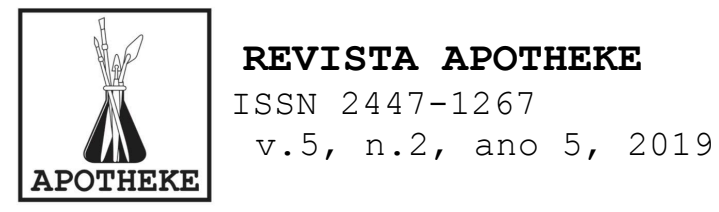

eu conseguia encontrar alguma pedra nova com alguma cor rara, dentro dos limitados matizes disponíveis, e que eu ainda não tivesse utilizado.

Depois, passei a desenhar em uma pequena área de terra, delimitada sob forma de retângulo, em frente à antiga morada rural dos meus pais. Sobre o chão nivelado de areia úmida, eu espalhava uma fina camada de areia seca e, então, riscava com o auxílio de espinhos de laranjeira ou limeira. As linhas ficavam nítidas, e a areia removida levemente com a mão permitia introduzir variações de luz e sombra. Havia um problema, no entanto, com os espinhos. A ponta deles se desgastava rapidamente, e considerando que eu costumava desenhar por cerca de uma a duas horas diárias. Em algum momento, se tornou difícil encontrar e repor o estoque de espinhos longos adequados para a atividade de desenho.

Como meu pai possuía uma oficina na qual, por vezes, ele realizava pequenos consertos e trabalhos de funilaria. Passei a pesquisar um modo de construir algum tipo de riscador que fosse flexível e resistente à abrasão da areia. Tentei com tiras de latas de azeite dobradas, mas não deu certo porque a ponta de lata era relativamente macia e se dobrava com muita facilidade. Depois, tive a ideia de utilizar as lâminas de barbear usadas pelo meu pai, recortando-as, longitudinalmente, para fazer uma ponteira que, por sua vez, era encaixada em um cabo de lata ${ }^{5}$ dobrada. Foi a solução mais adequada, pois a flexibilidade da ponteira de aço permitia curvas suaves e exatas além das variações de linha por meio de inclinações do cabo. Elas eram mais duráveis do que os espinhos, mas, com o passar do tempo, notei que mesmo essas pontas metálicas se desgastavam pelo atrito com a areia. A compra de vários blocos de papel necessários à quantidade de

5 folha-de-flandres: material metálico resistente e flexível ferro e aço de baixo teor de carbono revestido com estanho. 


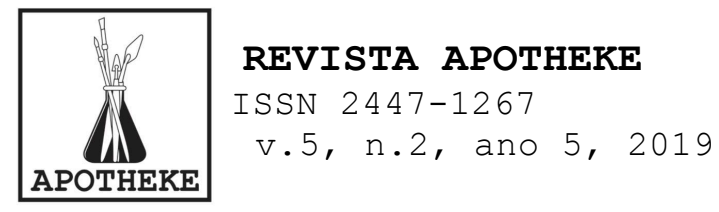

desenhos que eu fazia, não era uma alternativa viável para a situação econômica de minha família. Então posso dizer que a areia e as ponteiras de aço foram o material básico que usei para aprender a delinear as figuras de meu imaginário naqueles anos de infância.

Mas, como era possível aprender novas formas de desenho vivendo em uma área rural pobre e, na época, sem acesso à eletricidade? Meu contato com ilustrações se dava basicamente por meio das revistas em quadrinhos. Geralmente, minha mãe vendia produtos coloniais para 0 dono de uma banca de revistas na cidade de Faxinal do Soturno (RS), e ele doava algumas revistas. Naquela época, as edições que não eram vendidas tinham apenas as capas removidas e reenviadas como comprovante para a distribuidora. O restante da publicação geralmente era descartado. Desse modo, mesmo sem conhecer as capas originais, eu podia ter acesso à vários títulos de quadrinhos das editoras Abril, Bloch e Vecchi. Com seus super-heróis, caubóis do velho oeste americano e personagens zoomórficos infantis.

Nos desenhos feitos na areia, eu inventava histórias que davam uma continuidade verossímil para certos enredos iniciados nos quadrinhos que eu lia. Logo, passei a criar personagens autorais, mas que ainda com grande semelhança em relação às referências americanas e italianas. As histórias eram organizadas em edições com capa, editora fictícia e numeração sequencial, e tinham ciclos que se desdobravam em novas edições nos dias seguintes. As narrativas eram criadas conforme o ritmo das cenas, que eram desenhadas e logo a seguir apagadas, quadro após quadro no mesmo espaço de terra. Nessa época, eu costumava desenhar até cansar ou, pelo menos, até minha mãe interromper e avisar que eu devia fazer alguma outra atividade, ou para lembrar que eu deveria usar um chapéu de palha, caso decidisse prosseguir desenhando sob a intensa luz do sol. Ao levantar daquela posição, em que eu 


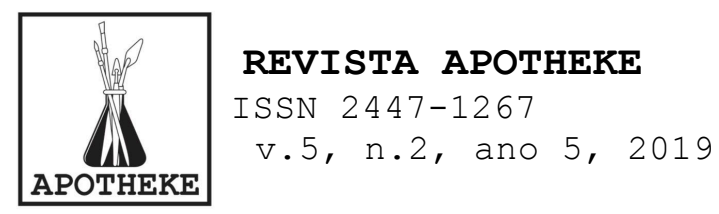

permanecia, por longo tempo, sentado no chão ou sobre uma pequena laje de pedra, por vezes sentia tonturas. Minha visão escurecia e, momentaneamente, eu tinha a ilusão de ver papéis brilhantes caindo do céu, provavelmente por efeito da hipotensão ortostática durante a readaptação à postura em pé.

Durante essa época, meus traços evoluíram, naturalmente, ficando mais sintéticos e estilizados, de modo que os rostos e corpos dos personagens podiam ser feitos de modo mais rápido, sem que eu me desconcentrasse da narrativa da história a ser elaborada ao mesmo tempo em que a sucessão de desenhos era realizada. Como, até então, eu não tinha nenhum treinamento formal sobre como desenhar a figura humana, lembro que buscava imaginar um movimento em escorço e começava o desenho sempre pela forma dos pés. E, a partir deles, estabelecia a direção das linhas seguintes. Em algum momento, eu havia percebi que as figuras dos quadrinhos faziam uso de algum tipo de razão proporcional. Era o que permitia que os desenhos mantivessem dimensões relativas constantes em diferentes enquadramentos, tanto nas cenas próximas, quanto nas distantes, mas eu não conseguia identificar qual era o módulo padrão utilizado. Então, desenvolvi meu próprio sistema proporcional baseado no tamanho do antebraço. Não era muito prático, mas funcionava, moderadamente, para corrigir situações em que eu percebia que o desenho de algum membro parecia estranho pelo uso de alguma dimensão exagerada.

\section{A aprendizagem prática do desenho}

Aos doze anos fui para a cidade de Nova Palma (RS), onde passei a trabalhar meio turno em uma fábrica de móveis e, no turno inverso dava continuidade aos estudos do Ensino Médio. Nesta época, comprei um curso de desenho artístico pelos 


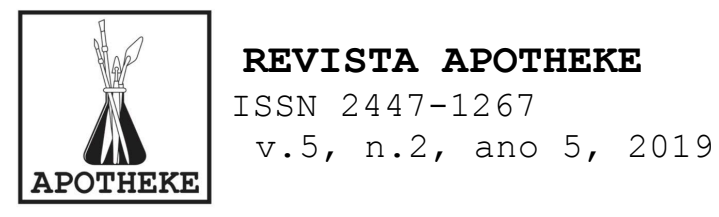

correios $^{6}$, e por meio dele descobri que a cabeça era o módulo tradicional utilizado para controlar a proporção nos desenhos de figura humana. Também foram úteis as noções de anatomia, proporções no desenho de rostos e a técnica do desenho de letras e noções básicas sobre harmonias de cores.

$\mathrm{Na}$ biblioteca pública da cidade, localizei um livro sobre cavalos. Em meus antigos desenhos de faroeste, realizados na areia, muitas vezes tive que desenhá-los, mas quase nunca conseguia resultados satisfatórios. Então passei a praticar, a partir das imagens fotográficas impressas naquele livro, até conseguir formular um esquema básico, das proporções e detalhes anatômicos, que eu passei a utilizar regularmente. Para complementar minha renda, passei a realizar serviços de pintura de letras em placas e fachadas de prédios comerciais, ilustrações para serigrafia, e as primeiras tentativas de realizar retratos à lápis, sem muita qualidade. Eu já não dispunha de tempo suficiente para praticar o desenho como diversão, mas ainda fazia alguns cartuns e caricaturas, e procurava completar um caderno de desenhos com desenhos coloridos com giz de cera e lápis de cor de personagens de filmes e super-heróis das histórias em quadrinhos da década de 80. E, assim, sem que as pessoas soubessem quanto tempo, até então, eu já havia dedicado à prática do desenho, logo passei a ser relativamente conhecido naquela cidade, influenciada pelo imaginário religioso, como alguém naturalmente agraciado com o "dom" do desenho.

Aos dezesseis anos fui para a cidade de Santa Maria (RS), estudar como aluno interno do Seminário são José. Lá, todas as atividades tinham horários regrados, e nos eram reservadas cerca de duas horas diárias para os estudos escolares. Mas, seguidamente, surgiam ocasiões em que eu era

6 Era um curso técnico à distância de desenho artístico e publicitário de uma instituição tradicional desse ramo localizada em São Paulo, SP. 


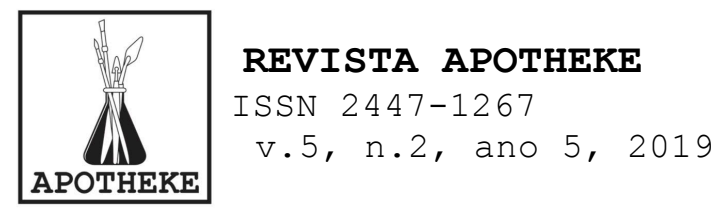

solicitado para ilustrar cartazes religiosos, pequenos cenários de teatro escolar, e caricaturas para um tradicional jornalzinho daquele colégio. Um ano e meio mais tarde, meu nome foi lembrado quando a prefeitura do município de Nova Palma necessitou contratar um desenhista. Fui convidado a retornar àquela cidade para trabalhar em um cargo de confiança no departamento de engenharia. O problema é que eu não tinha formação em desenho técnico, e a atividade consistia em auxiliar um dos engenheiros daquela instituição a montar e organizar pranchas de prédios com plantas baixas, vistas, cortes, fachadas e estruturas isométricas, além de mapas do município. Felizmente, o engenheiro foi paciente e me ensinou os detalhes do uso de canetas técnicas, aranha e normógrafos, gabaritos, esquadros e escalas. Depois disso, passei a auxiliá-lo também em desenhos de projetos particulares, e passei a pesquisar técnicas utilizadas para o desenho de construções arquitetônicas em perspectiva.

\subsection{A aprendizagem institucional do desenho}

Três anos mais tarde, eu ingressei no curso de graduação em Desenho e Plástica da UFSM, na habilitação de bacharelado. Meu principal objetivo era aperfeiçoar a técnica do desenho realista, mas ainda não tinha a mínima ideia do que era o mundo das artes. No primeiro ano, o momento mais traumatizante foi quando um professor solicitou que desenhássemos alguma cena imaginária e eu apresentei a ilustração de uma paisagem com abordagem naturalista. Num gesto surpreendente, ele pegou justamente aquela obra, entre as demais que estavam sendo avaliadas, e perguntou quem tinha feito aquilo! Eu me apresentei, e ele começou a expor as qualidades negativas daquele estilo de desenho quando comparadas ao que se espera de estudo artístico. Fiquei bastante frustrado e pensei que realmente tinha escolhido o curso errado. Mas em compensação, eu também havia conhecido 


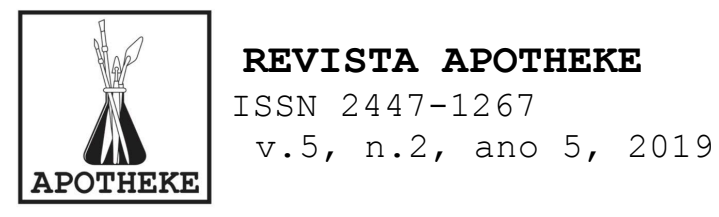

outro professor com uma abordagem um pouco mais tradicional e exigente quanto ao nível de correção dos desenhos de observação. Então decidi permanecer no curso por mais algum tempo porque, pelo menos, este professor poderia me conduzir ao meu objetivo inicial na aprendizagem desenho: a execução de imagens realistas.

Era o início da década de 90, e o curso tinha uma ênfase bastante voltada às variantes históricas do modernismo e às abordagens figurativas estilizadas. Poucos alunos conseguiam persistir e desenvolver trabalhos com tendências mais naturalistas. Um colega de estudos, com um excelente nível técnico no desenho de retratos não resistiu às frequentes críticas e pressão psicológica das declarações que aquele tipo de trabalho não era arte, mas apenas uma ilustração sem valor estético, e desistiu do curso. Porém, fora do período de aulas, por necessidade de subsistência, eu continuava a realizar desenhos técnicos de arquitetura e a utilizar o desenho mais tradicional em retratos, e pinturas de estandartes com imagens santos para as comunidades religiosas interioranas de Nova Palma. Foi aí que, aos poucos, percebi que mesmo as aulas não afinavam com meu objetivo, pelo menos, auxiliavam para o desenvolvimento de algumas habilidades que eu valorizava. Um exercício de proposto pelo professor de pintura, no qual deveríamos nos esforçar para encontrar o exato matiz da pintura original aguçou minha percepção para as sutilezas existentes entre as cores que no cotidiano eu considerava semelhantes. As exaustivas séries de desenhos de observação a partir de copos, haviam facilitado a identificação de estruturas e o melhorado a rapidez na execução de esboços de objetos em perspectiva.

Por algum tempo, também tentei resistir à orientação dominante no curso e preservar um traço mais acadêmico. Então uma banca de avaliação advertiu: mesmo que eu não reprovasse naquele semestre, isso inevitavelmente iria acorrer. Pois, 


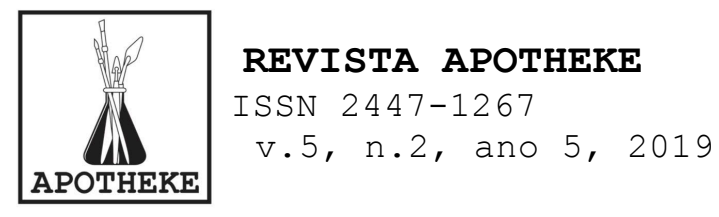

não notavam qualquer mudança significativa na evolução do meu desenho ou afinidade com as orientações fornecidas em semestres anteriores. Portanto, eu deveria refletir sobre meus objetivos naquele curso, pois talvez meu futuro estivesse no desenho industrial e não nas artes plásticas. No fundo, acho que eles tinham dúvidas se eu tinha capacidade de estilizar formas e usar cores de modo não convencional. Então decidi demostrar que eu realmente tinha condições de fazer o que eles esperavam, mesmo que achassem que o desenho tradicional fosse uma característica limitante para minha expressão artística. Abandonei abordagem naturalista, joguei tintas de modo aleatório, rasguei papéis, fiz colagens e explorei várias possibilidades formais do modernismo. E, então, finalmente recebi um elogio: “Agora sim, podemos ver que seu desenho realmente evoluiu!". Eu consegui a aprovação, mas, subjetivamente, era como vivenciar, continuamente, uma grande mentira. Eu não acreditava no que eu estava fazendo, não sentia que aquelas formas estilizadas fossem minhas, ou oriundas de uma necessidade real. No final do semestre, retornei para casa, reuni todos os trabalhos daquele período de estudos, e os queimei. E, daquele momento, até o final do curso, não voltei a praticar o desenho tradicional em aula, e, também, não dei continuidade às experimentações formais que eu não via sentido. Mas, encontrei um meio termo nas figuras simplificadas, semi-estilizadas, inseridas em um espaço de representação plano, as quais continuei a utilizar até o final do curso.

Após realizar uma pintura mural como trabalho de conclusão do bacharelado em desenho e plástica, continuei vinculado à graduação por mais um ano, frequentando algumas disciplinas complementares de um curso licenciatura em artes visuais. Esse curso possuía um currículo novo, mas, na época, ainda não havia recebido aprovação do Ministério da Educação e Cultura, por isso optei por abandoná-lo para dar 


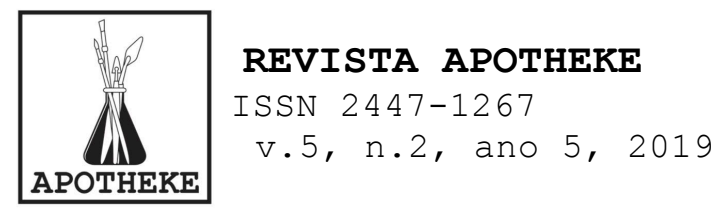

continuidade aos estudos em nível de pós-graduação. Nesse período, também trabalhei, com mais dois colegas, auxiliando meu professor orientador do bacharelado, na execução de um mural na fachada do prédio do Hospital Universitário de Santa Maria (RS). E, enquanto isso, continuei a refletir sobre meu futuro profissional. Eu gostava de desenhar de modo tradicional, mas, via que este tipo de desenho não parecia corresponder com as expectativas acadêmicas locais na época.

Também tive que reconhecer que não possuía a personalidade estereotípica de um artista visual, pois não gostava de ser notado, de mostrar meus trabalhos e nem do ambiente social normalmente relacionado às exposições de arte. O que despertava meu interesse o estudo da parte técnica e histórica da arte, da pré-história ao neoclassicismo. Mas, a arte moderna, e a contemporânea, não chamavam a minha atenção. Durante a graduação eu havia estagiado por dois anos na Escolinha de Artes da UFSM, e dessa experiência, somada às atividades das disciplinas complementares da área de licenciatura, não havia considerado satisfatória a atividade da docência de crianças. Entretanto, achava estimulante 0 ensino de adultos, porque nele havia questionamentos que eu julgava mais desafiadores, e me obrigavam a fazer o que mais gostava: pesquisar fundamentos os teóricos da arte. Por isso, realizei a seleção para o mestrado em artes visuais da UFRGS, na área de história, teoria e crítica da arte. Nos anos seguintes me dediquei a isto, e, como consequência, foi o período em que menos desenhei. Ainda usava as técnicas aprendidas na graduação em artes para fazer esboços rápidos de imagens em cadernos de estudo dedicados aos seminários de história da arte, mas sentia que já não tinha energia suficiente para me dedicar ao desenho.

Um relato sobre o ensino do desenho 


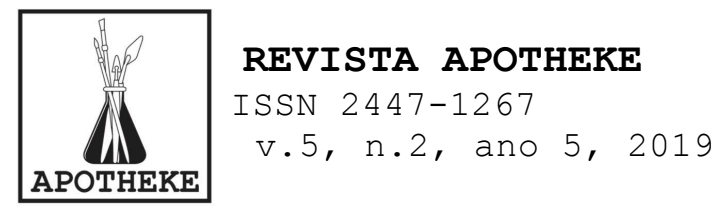

Ainda durante o doutorado em artes visuais, também realizado na UFRGS, comecei a trabalhar como professor do curso de Design de Moda da FEEVALE, em Novo Hamburgo (RS), na disciplina de Desenho da Figura Humana. Era a minha primeira experiência no ensino superior, e precisava ensinar fundamentos tradicionais de proporções e anatomia de corpos idealizados em um semestre. Então, comecei a pesquisar os sistemas de proporções existentes, e minhas principais referências, na época, eram autores espanhóis como José M. Parramón (1986) e Alfonso Calderón (1981), além do, brasileiro, Alfredo Galvão (1941). Mas, percebi que havia contradições sobre detalhes proporcionais da figura humana entre os cânones divulgados nestes livros. Por isso, tinha que me esforçar para encontrar um modo de conciliar as diversas abordagens e uma síntese a partir do material visual que eu tinha acesso. Somente mais tarde, conheci a reedição do livro clássico de Paul Richer (1986) sobre o desenho da figura humana em dimensões naturais ${ }^{7}$ e, em anos ainda mais recentes, as obras de Valerie L. Winslow (2015; 2016); o estudo sobre as proporções dos corpos idealizados de Gottfried Bammes (2017); e os livros de Fréderic Délavier (2000; 2003), em princípio elaborados para o ensino de exercícios físicos de musculação, mas que servem satisfatoriamente para o estudo desenho de anatomia muscular. obras que continuo utilizando, com poucas adaptações pessoais, em minhas aulas de desenho da figura humana.

Ainda durante a experiência de ensino na FEEVALE, percebi que os estudantes de artes, geralmente, já possuem alguma experiência anterior no desenho da figura humana. Ao enfrentarem dificuldades, com frequência, recorrem a esses

\footnotetext{
7 Tradução inglesa do livro Anatomie artistique: description des formes extérieures du corps humain au repos et dans les principaux mouvements, originalmente editado em 1890, e ampliado em 1906 na edição da Nouvelle Anatomie Artistique du Corps Humain: cours practice et élementaire.
} 


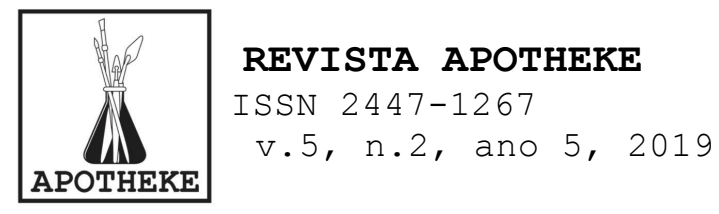

sistemas individuais de proporções, com o quais já se acostumaram, para estruturar novos desenhos. E, mesmo tendo passado por uma disciplina em que são treinados a utilizar proporções tradicionais baseadas em cânones de 7,5 ou 8 cabeças, sempre que solicitados a desenhar corpos de memória tendem retornar à segurança dos antigos esquemas que já conheciam. Por isso, após 2009, ao lecionar uma disciplina semelhante, na UFSM, adotei um método de avaliação qualitativa sem notas, em paralelo à avaliação exigida para o curso. No primeiro dia de aula, antes de passar qualquer informação técnica, eu solicitava que os alunos desenhassem um casal humano com corpos idealizados. Ao finalizarem os desenhos eu os recolhia e guardava. Mas, avisava que estes desenhos iniciais somente seriam revisados e avaliados no final do semestre. Então as aulas prosseguiam normalmente com explanações teóricas sobre proporções e anatomia, exercícios práticos a partir de imagens e poses de modelo vivo.

Quando chegava a última aula do semestre, eu solicitava que os alunos refizessem o exercício da primeira, sem consulta aos exercícios e anotações anteriores. Pois, desse modo, podíamos avaliar, conjuntamente, em que pontos a figura inicial havia se modificado, que detalhes dos cânones tradicionais eles realmente havia aprendido e tinham capacidade de recuperar de memória. $E$, em que detalhes, continuavam a repetir o conhecimento anterior à disciplina de desenho da figura humana. Com esse momento de reflexão, ficavam evidentes os progressos decorrentes dos novos conhecimentos anatômicos adquiridos, e os alunos passavam a ter ciência do longo caminho que ainda necessitaria ser trilhado, caso desejassem evoluir no desenho tradicional no sentido de substituir gradualmente os esquemas préexistentes. São situações com as quais me solidarizo, pois ainda lembro o quanto foi difícil para mim, no passado, o esforço de substituir a abordagem pessoal de desenho da 
figura humana com figuras desenhadas a partir do pé, por figuras com estruturas proporcionais modulares tendo como base o tamanho da cabeça.

Quanto às técnicas de desenho de observação que utilizo no ensino de estruturas em perspectiva, eu as desenvolvi gradualmente ainda no tempo em que era aluno de graduação. Em uma disciplina inicial do curso o professor exigia que apresentássemos, pelo menos, vintes desenhos de um objeto simples como um copo de cozinha, em várias posições. Eu compreendia que a repetição parecia ser realmente um dos elementos necessários à aprendizagem e logo me acostumei à rotina. Mesmo assim, percebia que alguns colegas, apesar do esforço tinham maior dificuldade em melhorar a apreensão da constante variabilidade de formas e proporções dos objetos em escorço.

No passado, durante minha graduação, também tive algumas dificuldades, no caso, a de manter a regularidade dos detalhes fisionômicas em um exercício com retratos reproduzidos em série. Neste, era solicitado que desenhávamos nove rostos por página do caderno de estudos. Em cada sequência escolhíamos um retrato de referência e repetíamos três vezes a mesma imagem buscando a cada etapa verificar os erros cometidos, ao mesmo tempo em que se buscava a progressiva síntese dos traços necessários para captar apenas as características essenciais da pessoa retratada. Durante este exercício, eu aprendi uma das lições que considero mais valiosas no desenho de observação, e que rememoro a meus alunos: a repetição é necessária para a aprendizagem, mas sem os esforços progressivos de correção ela não leva a progressos significativos. Acredito que seja uma regra que pode ser generalizada para um grande número de habilidades. $\mathrm{Na}$ situação menos desejável, o desenvolvimento das habilidades em desenho figurativo pode se processar de modo semelhante aos de um motorista comum, que apesar de ter 
experiência de várias décadas executando manobras repetitivas no volante de um carro, mesmo assim, não logra o desenvolver habilidades próximas às de um piloto profissional.

Para concluir esse ensaio autorreflexivo, com uma síntese a respeito do que acredito sobre os fundamentos necessários para que haja a aprendizagem do desenho, gostaria de reafirmar alguns princípios. Entre estes, para haver o desenvolvimento das habilidades básicas do desenho de observação são necessárias duas coisas, além do óbvio exercício constante do desenho. Em primeiro lugar é fundamental gostar profundamente da atividade, pois sem essa motivação a repetição se torna enfadonha. Em segundo, é preciso exercitar a autocrítica após cada desenho realizado para que se perceba quais são as dificuldades recorrentes e, então, elaborar estratégias para superá-las nas próximas tentativas. A avaliação de um professor ou o olhar crítico de um colega podem ajudar na fase inicial de desenvolvimento, mas somente o esforço individual da repetição consciente, sob novas bases e com graus de dificuldade crescentes, leva ao aperfeiçoamento técnico. Repetição sem reflexão é desperdício de tempo e energia que assegura, no máximo, a persistência nos mesmos erros. Por isso, costumo afirmar que o principal momento de aprendizagem do desenho se dá durante a pausa, na qual avaliamos o resultado dos esforços anteriores.

\section{Referências}

BAMMES, Gottfried. The Complete Guide to Anatomy for Artists \& Illustrators: Drawing the Human Form. England: Kent: Watson-Guptill, 2017 .

CALDERÓN, Alfonso. Dibujando la figura humana. 5 ed. Barcelona: CEAC, 1981 .

DÉLAVIER, Frédéric. Guia dos movimentos de musculação para mulheres: Abordagem anatômica. São Paulo: Manole, 2003.

DÉLAVIER, Frédéric. Guia dos movimentos de musculação: Abordagem anatômica. São Paulo: Manole, 2000 .

GALVÃo, Alfredo. Noções de Anátomo-Fisiologia Artística e de Proporções: proporções da figura humana e do cavalo. Rio de Janeiro: Globo: 1942. 
HAYANO, David M. Auto-Ethnography: paradigms, problems, and prospects. In: Human Organization. New York: Society for Applied Anthropology. 1979, Vol. $38, \quad \mathrm{n}$. $1, \quad \mathrm{p}$ 99-104. Disponível em: https://www.jstor.org/stable/44125560. Acesso em: 26 jun. 2019.

PARRAMÓN, José Maria. Cómo dibujar la figura humana. Barcelona: Parramón, 1986.

RICHER, Paul. Artistic Anatomy. Reprint. New York: Watson-Guptill, 1986.

WINSLOW, Valerie L. Classic Human Anatomy in Motion: The Artist's Guide to the Dynamics of Figure Drawing. Reprint. New York: Watson-Guptill, 2015 .

WINSLOW, Valerie L. Classic Human Anatomy: The Artist's Guide to Form, Function, and Movement. Reprint. New York: Watson-Guptill, 2008.

\section{Altamir Moreira}

Currículo Lattes: http://lattes.cnpq.br/6180609329576172

Professor Adjunto do Departamento de Artes Visuais, do Centro de Artes e Letras, da Universidade Federal de Santa Maria. Possui Doutorado (2006) e Mestrado (2002) em Artes Visuais, com ênfase em: História, Teoria e Crítica da Arte pela Universidade Federal do Rio Grande do Sul e Bacharelado em Desenho e Plástica (1997) pela Universidade Federal de Santa Maria. Pesquisa temas relacionados à iconografia da pintura mural religiosa e da paisagem regional. Participou da Assessoria Ad Hoc do CNPq na área relacionada a desenho. Em cursos de graduação lecionou conteúdos relativos à: Pintura, Desenho da Figura Humana, Desenho Geométrico, História da Arte e Apreciação da Arte; Na pós-graduação: Crítica em Arte, Arte: interações e resistências culturais e Metodologia da Pesquisa. Desenvolve uma prática artística figurativa com temática relacionada à paisagem regional.

Recebido em 15 de julho de 2019. Aprovado em 15 de agosto de 2019.

ORCID: https://orcid.org/0000-0002-6251-0079 